\title{
PATAGONIA: RETORNO A LO DESCONOCIDO, LA PARADÓJICA REMINISCENCIA DE UN PAISAJE VACÍO ${ }^{1}$
}

PABLO CHIUMINATTOa \& RODRIGO DEL RÍO

\begin{abstract}
RESUMEN
Tradicionalmente se asocia al paisaje americano con un despliegue exótico. En el caso de la Patagonia cierta monotonía reemplaza la exhuberancia y el exotismo por la inscripción imborrable de un territorio aparentemente yermo. En el análisis de algunos relatos de viajeros ingleses (Ch. Darwin, F. Dixie y W. H. Hudson) se observa el testimonio de esta experiencia como una forma de nomadismo cultural, donde confluyen elementos propios del titubeo descriptivo ante el encuentro de una geografía poderosa. Un tópico recurrente en esas descripciones es la paradójica persistencia de un "paisaje vacío". El fundamento de su permanencia mezcla sorpresa y decepción. En este artículo buscamos recuperar, comparar y analizar la escritura de esta experiencia. Con este fin integramos la práctica comparativa, con las poéticas de lo geográfico, así como una elaboración de la presencia del paisaje como determinante estética.
\end{abstract}

PALABRAS CLAVE: Patagonia, territorio, paisaje, nomadismo, literatura de viaje.

\section{PATAGONIA: RETURN INTO THE UNKNOWN, THE PARADOXICAL REMINISCENCE OF AN EMPTY LANDSCAPE}

\section{ABSTRACT}

Traditionally, American landscape is associated with an exotic deployment. In the case of $\mathrm{Pa}$ tagonia, a kind of monotony replaces the exuberance and exoticism for the indelible inscription of an apparently desolate territory. In the analysis of some narratives of English travelers (Ch. Darwin, F. Dixie and W. H. Hudson), the testimony of this experience can be observed as a form of cultural nomadism; where descriptive elements of hesitation join before the meeting of a powerful geography. A recurrent theme in these descriptions is the paradoxical persistence of an "empty landscape". The foundation of its permanence is an experience that blends amazement and disappoint-

a Facultad de Letras, Pontifica Universidad Católica de Chile, Avda. Vicuña Mackenna 4860, Macul, Santiago Chile.

b Department of Romance Languages and Literatures, Harvard University, Boylston Hall, 4th Floor, Cambridge, MA 02138, rdelrio@g.harvard.edu

1 Este artículo forma parte del proyecto CCA 2013 - 1461: "Terra Australis: geopoéticas del Pacífico sur", Vicerrectoría de Investigación, Pontificia Universidad Católica de Chile 
ment. In this article we attempt to retrieve, compare and analyze the writing of this experience. We integrate comparative practice with the poetics of the geographical, as well as an elaboration of the landscape's presence as an aesthetic factor.

KEY WORDS: Patagonia, territory, landscape, nomadism, travel literature

\section{IMAGINAR LA PATAGONIA}

Durante gran parte de su historia, la Patagonia ha atraído la imaginación viajera. Este proceso no ha estado exento de contradicciones, tanto históricas como literarias. Una de estas contradicciones está caracterizada en los registros escritos de los exploradores europeos al territorio, quienes a pesar de declarar muy marcadamente los aspectos deficitarios del lugar, en comparación con parajes de más al norte, no pueden borrar el paisaje patagónico de su memoria. En este artículo proponemos estudiar pasajes de tres exploradores ingleses, Charles Darwin (1809-1882), Lady Florence Dixie (1855-1905) y William Hudson (1841-1922), cuyos textos muestran con claridad los rasgos de esta disonancia. En este artículo se analizan sus primeras visiones de la Patagonia y el estrecho de Magallanes, donde parece estar la marca del principio literario que informa su escritura.

Adentrarse en la copiosa literatura decimonónica de viajeros ingleses al sector patagónico requiere ocuparse de la heterogeneidad de las voces que componen la imagen del territorio. Distintas jerarquías al interior de este campo de imaginación territorial sobredeterminan la recepción de cierta idea de la Patagonia. Decididamente, el relato de Charles Darwin provee un núcleo, acaso una especie de punto fundacional, desde el que luego se proyecta la Patagonia en la imaginación viajera de los exploradores ingleses del periodo. La propuesta de este estudio es rastrear cierta atracción estética en la constitución literaria de la imagen patagónica en la forma de paisaje. Por esa razón, partiendo desde Darwin, buscamos un tropo que permitiera la configuración de un diálogo relevante entre estos relatos de viajeros. En este caso, la paradójica figuración del territorio patogónico como un paisaje vacío. Este tropo, como se verá en lo que sigue, se encuentra claramente reproducido tanto por Florence Dixie como por William Hudson, autores que sirven de sustento a esta figuración específica de la Patagonia. El interés en capturar este corpus acotado de relatos determina la eficacia de la operación crítica, que se vería transformada, sin duda, por la inclusión de voces que matizan, e incluso antagonizan, con la descripción de Darwin. Este es el caso de Thomas Bridges (1848-1898) (Malvestitti, 2010), quien polemiza con la versión que Darwin da de los habitantes de la Patagonia, lo que implicaría un efecto sobre la construcción literaria del paisaje vacío. Otro caso que aportaría un debate diferente sería el de William Greenwood (1849-1923) (Martinic, 2002) o William Blain (1852-1924) (Harambour et al. 2015), quienes habitan de forma activa en la Patagonia, aportando un relato de poblamiento (e incluso se diría colonización económica), más que una mirada que pueda considerarse parte propiamente de la literatura viajera. Estos, entre otros ejemplos, sin duda enriquecerían la reflexión estética que se pretende construir en este artículo. Sin embargo, consideramos importante partir con la construcción poética de Charles Darwin y dos de sus más directos interlocutores, para luego dejar abierto un espacio de debate crítico que pueda especificar la impronta estética del paisaje patagónico desde la mirada de los exploradores ingleses en dos hitos temporales distintos y distantes.

El ensayo se divide en cuatro partes. La primera describe la intensa atracción que la Patagonia generó en ellos, centrándose en la impresión inolvidable del territorio y cómo queda plasmado en sus textos. La segunda presenta una la manera en que los escritos de estos exploradores pueden ser estudiados de una forma tal que ponga el foco en el territorio, en lugar de la obra aislada. Una tercera parte explora las marcas textuales en las que se constituye la Patagonia desde el imaginario paradójico de un paisaje aparentemente yermo, como un desierto de agua. La parte final del ensayo construye una propuesta de interpretación de la imagen recurrente de un "paisaje vacío", desde un afán exploratorio de la mirada, centrándose especialmente en los objetivos de las travesías de estos viajeros. 


\section{RELATOS DE VIAJEROS INGLESES}

Charles Darwin llega a la Patagonia en 1832. Según su propio testimonio, el paisaje es desolador. El naturalista británico observa la extensión de las planicies patagónicas como una tierra abandonada por la gracia, un infierno frío y dantesco: "estas planicies son descritas por todos por ser las más miserables e inútiles. Se caracterizan solo por sus posesiones negativas; sin habitaciones, sin agua, sin árboles, sin montañas, sostienen exclusivamente unas pocas plantas enanas" (Darwin, 1909, p. 506). ${ }^{2}$ Sin embargo, Darwin encuentra en el territorio patagónico la inspiración para desarrollar las teorías que luego lo pondrían en el canon científico y cultural de la humanidad. Además, consigue relatar cada una de las escenas en un extenso y acucioso diario. ¿Por qué estas planicies "miserables e inútiles" merecían tanta atención? Él mismo se da cuenta de esta disonancia. Una vez de regreso en Londres, rememorando la Patagonia, no puede evitar hacerse la pregunta central de este breve estudio: "¿Por qué, entonces, -y no es exclusivamente mi caso- estos áridos desechos han tomado tan firme posesión de mi mente? (Darwin, 1909, p. 506).

Tiempo después de Darwin otros viajeros ingleses se enfrentan a una perspectiva similar. Describen la contradictoria atracción por la Patagonia. Un ejemplo es el de Lady Florence Dixie, escritora y espía para el gobierno británico, quien a su regreso a Londres publica Across Patagonia en 1880. Otro caso es el del ornitólogo argentino-británico William Henry Hudson, radicado en Inglaterra, quien publica Idle Days in Patagonia en 1893. William Hudson, por su parte, interrumpe su investigación sobre aves patagónicas para sumirse en la contemplación de los páramos inmóviles, casi desérticos, de la región austral del continente americano. La experiencia de Darwin se repite en ellos. Los paisajes patagónicos permanecen en la memoria de ambos viajeros, incluso, sobre otros panoramas más coloridos, a pesar de que lo que despierta el recuerdo sea un paisaje estéril.

William Hudson cita textualmente la pregunta de Darwin (Hudson, 1923, p. 207). Pero a diferencia del desconcierto del naturalista inglés, el ornitólogo intenta una respuesta. Según Hudson, Darwin falla en percibir los efectos particulares de aquel paisaje monótono en la sensibilidad. La memoria está íntimamente conectada al sentimiento. La fuerza emotiva de las planicies patagónicas tiene que derivar de una conmoción simultáneamente sensitiva y sentimental, "Sabemos que mientras más profundamente nuestros sentimientos son movidos por cualquier escena, más vívida y duradera será su imagen en la memoria -un hecho que explica el carácter comparativamente persistente de las imágenes que remiten al período de nuestra infancia, cuando somos más emocionales" (Hudson, 1923, p. 209).

Si se describen las emociones con sutileza, entonces, se pueden identificar las características que hacen tan intensa la imagen de este paisaje. Con $\mathrm{H}$. Thoreau como modelo, Hudson cree que la Patagonia devuelve al ser humano a un estado salvaje e infantil al mismo tiempo. Plantea que el estado de exaltación "puede solo ser atribuido a una reversión instantánea a condiciones mentales primitivas y completamente salvajes" (Hudson, 1923, p. 217). Desde esta perspectiva, el ser humano en soledad se vuelve semejante a un animal. De ahí que el hambre, la sed y el cansancio se presenten únicamente al momento de necesidad, nunca por motivos de comodidad. Así también los infantes muestran esta intensidad animal y primitiva: "Es en la infancia y en la niñez, cuando los instintos están más cercanos a la superficie, y listos para brotar a la actividad cuando la ocasión llame. La segunda naturaleza heredada es más débil en ese momento; y el hábito no ha progresado mucho en tejer su fina red de influencias restrictivas sobre la naturaleza primitiva" (Hudson, 1923, p. 220-1).

Aunque sugestiva, la explicación de Hudson hoy resulta poco convincente. El ornitólogo identifica correctamente que el problema de la permanencia de las imágenes patagónicas es un problema estético, pero su explicación está inevitablemente atada a la dicotomía decimonónica entre civilización y barbarie. Este paradigma se articula por medio de la metáfora de la infancia, que durante el siglo XIX fomentó "una lectura positiva de la infancia como una esfera separada de la experiencia humana. La infancia siempre ha sido 
considerada cercana al caos, por tanto necesitada del proceso civilizador" (Cosgrove, 2008, p. 114). Esta ideología como un proyecto civilizatorio presenta las tierras baldías de la Patagonia como un niño salvaje, que debía instruirse y disciplinarse por la mano de la madurez moderna. Este proceso permanece en un eje de comprensión que no reconoce la potencia epistémica de lo geográfico, más allá de los tropos descriptivos bajo los que se cree someter al paisaje. En este estudio nos hemos propuesto volver sobre la pregunta de Darwin e intentar una respuesta que indague en los textos de los autores antes mencionados. Una explicación de por qué la Patagonia sobrevive en la memoria de los viajeros. La hipótesis del artículo es que estos textos representan la Patagonia como un territorio nómade, descripción que depende de una distinción elaborada por Gilles Deleuze. Según este pensador, un territorio puede distribuirse en dos maneras. Por una parte, una distribución nómade, en la que "...ya no hay reparto de un distribuido, sino más bien repartición de quienes se distribuyen en un espacio abierto ilimitado, o, por lo menos, sin límites precisos. Nada corresponde ni pertenece a nadie, pero todas las personas están ubicadas aquí y allí, de modo de cubrir el mayor espacio posible" (Deleuze, 1968/2002, p. 73). Por otra parte, una distribución sedentaria, en la que las formas del territorio "están pues representadas como principio de reparto, que se consideran a sí mismo lo mejor repartidos. Semejante tipo de distribución por determinaciones fijas y proporcionales, asimilables a 'propiedades' o territorios limitados en la representación"(Deleuze, 1968/2002, p. 73). En este sentido, este ensayo propone dimensionar la forma en que los elementos de la descripción del territorio patagónico no se organizan por jerarquías, sino que generan una distribución nómade de fronteras abiertas a partir de la experiencia de estos exploradores. Se trata de un marco teórico que permite recuperar la experiencia geográfica en el texto y que integra la interacción con la presencia geográfica del territorio. De esta forma, se intenta mostrar la manera en que los textos de estos viajeros tratan de volver hospitalarios los elementos nómades del paisaje que, en otros contextos, permanecen en sus compartimientos estancos y usurpan la vitalidad de su movimiento intercultural.

\section{REPRESENTAR EL TERRITORIO. GEOPOÉTICA Y GEOCRÍTICA}

Los relatos de viajeros tienen una pretensión referencial, es decir, la conservación de la experiencia de la geografía por medio del registro y recopilación en la escritura. Sin embargo, su afán está sometido a los confines de cualquier relato. Imaginarios y fantasías, trasladados desde sus experiencias previas, reproducen las atractivas formas de una narración de viaje que se enfrenta a lo nuevo. En el caso de las crónicas, diarios y relatos de la Patagonia es posible preguntarse por la existencia metafórica de una estética patagónica, es decir, una forma específica de conocer y articular la experiencia de ese territorio.

De este modo, se hace preciso un modelo teórico que permita dar cuenta de los traslados literarios que afectan la escritura viajera (LivonGrosman, 2003; Pratt, 1992/2008). La lectura que proponemos da un giro hacia lo que se ha denominado geopoética, en el caso de Kenneth White (1992), o geocrítica, en el de Bernard Westphal (2001), en un intento de constituir una representación del territorio. Dicha relación será la base para la lectura de esta propuesta estética patagónica desde un espacio nómade, donde los elementos de dicha representación pierden sus límites precisos (Deleuze, 1968/2002). En este caso, se desplazan los elementos simbólicos en los que estos autores británicos piensan el paisaje del sur de América. Este desplazamiento se desenvuelve en constante interacción con las propuestas estéticas del romanticismo inglés (Paradis, 1981, p. 88). Especialmente en el caso de Darwin, se nota un desplazamiento desde una idea de una naturaleza ordenada, y por tanto de la función que el paisaje tiene en su captura, hacia una concepción científica, cuyo principio de acción sería desequilibrio (Paradis, 1981, p. 95). La experiencia de una naturaleza caótica, particularmente en sus visitas al cono sur americano, movilizan las ideas de Darwin a una idea orgánica, fluida, de la forma en la naturaleza, en la que el lenguaje y las metáforas románticas serían refuncionalizadas, desde un índice de la armonía de lo natural, hacia un instrumento de captura, medición y control de la naturaleza (Dear, 2015, p. 333). Así, el árbol como máximo ícono de esta mentada armonía y orden para la ideología romántica devie- 
ne en los árboles evolutivos darwinianos, cuyo fin sería la descripción de las leyes que organizan el sistema dinámico de la naturaleza (Paradis, 1981, p.108).

Kenneth White, crítico y filósofo escocés, enmarca en una serie de trabajos la urgencia de orientarse en nuevos espacios culturales. Según White, la creación e interpretación de textos debe superar la escena de la escritura y mirar hacia el exterior al que el texto apunta: el territorio. Su pretensión es mudar del libro a los mapas, o del libro en su autonomía y jerarquía sintética a libros que pueden funcionar como mapas: "...se ha dicho, y tenía que ser dicho (Korzybski fue el primero), que el mapa no es el territorio. Pero si quieres un sentido inicial e iniciático del mundo, ¿qué hay mejor que un mapa?" (White, 1992, p.166).

La literatura en el modelo de White no tendrá límites predefinidos por una lengua nacional, sino que se construirá en la multiplicidad de escrituras que intentan capturar la experiencia compleja de un lugar. La nueva alegoría del pensador será, por tanto, la de un nómade que cartografía su rastro a medida que aparece. Se abandona la representación para privilegiar los vestigios de la experiencia geográfica en la escritura. La lectura nómade de White origina el mundo y su lenguaje al mismo tiempo que lo experimenta.

¿Qué operación formal permite recuperar el fantasma escurridizo del territorio? El fin último de la geopoética será devolver la prioridad de la mirada hacia el territorio a través de las innovaciones y resistencias formales de la geografía en el texto. Bertrand Westphal construye un marco crítico en el que esta búsqueda textual se haga posible.

Westphal (2011), desde lo que ha llamado geocrítica, pretende comprender espacios reales por medio de entender su fundamento ficcional. Es decir, la manera en que las ficciones influyen sobre la representación de los espacios. Así, Westphal sugiere desplazar la preocupación egocéntrica por la obra hacia una crítica literaria que privilegie el territorio (Westphal, 2001, p. 111). Entonces, en lugar de centrar la atención en Darwin, por ejemplo, se intentará extraer la representación que en sus textos se hace de la Patagonia.

¿Cómo se asegura el foco en el lugar y no en el autor? Westphal sugiere que se puede lograr a través de una perspectiva que controle la influencia del autor, por medio de agregar diferentes puntos de vista. Westphal llama a este gesto la "multifocalización", procedimiento metodológico en el que se confirma que toda identidad cultural, incluyendo la del territorio, es un proceso constante de creación y recreación (Westphal, 2001, p. 128). Por tanto, se compararán las voces de distintos autores y su posición respecto al territorio.

La multifocalización determina el corpus que trabajaremos. Westphal admite que existen al menos tres puntos de vista que el observador puede adoptar frente al territorio. Por una parte, el endógeno, que es el punto de vista familiar y autóctono que se resiste a la mirada forastera (Westphal, 2001, p. 128). Por otro lado, el exógeno que representa la mirada del extranjero, origen de las representaciones exotistas del territorio (Westphal, 2001, p. 129). Por último, el punto de vista alógeno que se construye desde una mirada híbrida en la que el observador pasa por un proceso de familiarización vital con el lugar, pero permanece ajeno en comparación con un observador autóctono (Westphal, 2001, p. 129). En este artículo se ha escogido comparar las similitudes y diferencias de la mirada exógena, representada por Charles Darwin y Florence Dixie, ambos provenientes de Inglaterra, con una mirada alógena, representada por William Hudson, quien nace en Argentina, pero tempranamente realiza sus estudios en Inglaterra.

La selección del corpus y la preocupación por el territorio reflejan la prioridad de la mirada hacia la Patagonia a través de las innovaciones y resistencias formales de la geografía en el texto. De este modo podemos preguntarnos acerca de la proyección del paisaje sobre la mirada de ellos. En último término, ¿qué vieron? ¿qué recordaron en sus textos?

\section{ENTRAR AL LIENZO, REPRESENTAR PAISAJES VACÍOS}

Antes del análisis de los viajeros ingleses, conviene traer aquí un relato paralelo de la Patagonia. Uno de aquellos fundacionales del imaginario occidental patagónico se encuentra en el viaje de Hernando de Magallanes, quien llega a la región en 1520. El estrecho por el que ingresan los viajeros británicos, cuatro siglos después, lleva su nombre. 
A. Pigaffeta (1536/1986) hace suyas el relato de las peripecias de Magallanes en su libro Primer viaje alrededor del Globo, escrito en 1536. Es interesante reconocer los elementos de este relato, puesto que se contrapone al de los viajeros ingleses que comparamos aquí.

La mirada de Pigaffeta representa a la $\mathrm{Pa}$ tagonia desde una dimensión asociada a las antípodas. En cierto sentido, el viajero no cree descubrir una geografía antes ignota, sino reencontrar un paisaje prometido. Típicamente, la nominación Patagonia se atribuye a la sorpresa de los descubridores por el tamaño de los pies de los habitantes de las tierras australes, nativos Tehuelches (LivonGrosman, 2003). Pero, en realidad, parece más certera otra versión. La historia está en Gonzalo Fernández de Oviedo (1478-1557) cuando divulgó acerca del origen del nombre de los aborígenes $\mathrm{Pa}$ tagones (Rojas Mix, 1992, pp.78-79). Según esta versión, Pigaffeta habría asociado esta imagen a una narración de caballería conocida en la época, Primaleón de Grecia, en la que el protagonista zarpa a tierras lejanas para enfrentar un monstruoso contendiente, el Gran Patagón, un monstruo con cabeza de perro, pero dotado de intelecto humano. El cronista habría visto en los habitantes de la Tierra del Fuego una reaparición de esta visión literaria en la lejanía de las nuevas tierras descubiertas (Chatwin, $1977 / 2005$, p. 105).

La diferencia con los viajeros del siglo XIX que mencionamos antes como Darwin, Dixie $\mathrm{y}$ Hudson, es que el relator del viaje magallánico encuentra lo que conoce, busca volver a casa. Representa la Patagonia como un territorio sedentario. Tal como dijimos antes, en este tipo de representaciones se espera que las categorías tengan limites precisos. En el caso de Pigaffeta, se reduce por analogía las nuevas experiencias que el territorio ofrece a elaboraciones previas de su acerbo cultural europeo. De esta manera, evitando así la crisis de lo desconocido.

Los exploradores ingleses del siglo XIX, en cambio, se quedan con la Patagonia en la memoria sin intentar recuperar el mundo propio, sino comparando ese otro mundo. No esperan el paraíso o el infierno como Pigaffeta, no sueñan con las hijas

3 Aunque tuvo dos ediciones con otro títulos, el más conocido es Journal of Researches into the Geology de los ángeles, ni otras formas teratológicas. En su caso el paisaje patagónico, su experiencia, es el que afecta el conocimiento del viajero proveniente de las regiones centrales del viejo continente.

Ahora, analizaremos en particular las escenas inaugurales con las que estos exploradores británicos recuerdan su ingreso a la Patagonia. En ellas es posible rastrear la raíz del efecto en la memoria de las tierras australes en su escritura. ¿Cuál es la forma literaria de este efecto? La representación de la Patagonia como un "paisaje vacío".

Darwin escribe su viaje por la Patagonia en el contexto de la expedición abordo del Beagle, junto al capitán Fitz Roy, en su obra publicada en $1838^{3}$. Uno de los pasajes más dramáticos en de este diario tiene ocasión en Puerto del Hambre. Reconocido por su trágica historia, el paisaje acompaña la intensidad de la escritura del naturalista inglés. Este fragmento muestra una imagen inmóvil del estrecho de Magallanes, la entrada a la Patagonia: "Nunca he visto una perspectiva más infeliz; los bosques umbrosos, manchados de nieve, podían únicamente ser vistos confusamente, a través de una lluviosa y brumosa atmósfera." (Darwin, 1909, p. 238).

Las planicies patagónicas se exhiben como un territorio yermo, seco, inhóspito para la sensibilidad del inglés (Stafford, 1984, p. 367). El asombro ocupa sus reflexiones influidas por el gusto europeo de paisajes humanizados. En la misma línea, su contemporáneo John Ruskin, historiador británico y teórico del arte, recomienda, pensando en los motivos pictóricos "...solo los fenómenos naturales en su directa relación con la humanidad estos tendrán que ser sus temas en el paisaje" (Ruskin, $1871 / 2007$, p. 5). Esto no impide el deseo de conocer nuevos lugares. Darwin penetra en el paisaje descrito. Pero ya no se reconoce como un mero observador, sino que explora las posibilidades de recorrerlo y habitarlo, aunque sea temporalmente. Describe su ascenso a la más alta montaña del sector, el monte Tarn,

Tan espeso era el bosque, que era necesario recurrir constantemente a la brújula; porque cada hito, aunque estábamos en un

and Natural History of the various countries visited by H.M.S. Beagle. 
país montañoso, era inaccesible. En los profundos barrancos, la escena mortuoria de desolación excedía toda descripción; fuera había un ventarrón pero en estas hondonadas, ni siquiera un soplido de viento movía las hojas de los árboles más altos. Tan triste, fría y húmeda era cada parte, que ni siquiera los hongos, el musgo o los helechos podian florecer. (Darwin, 1909, p. 239).

La Naturaleza en pleno acude a confirmar que aquel lugar no es apto para el ser humano. La naturaleza aparece en paralelo a su dimensión mística con figuras emanadas de la tradición romántica inglesa. Mientras la literatura y la poesía -así como la pintura- imagina paisajes infinitos, Darwin los experimenta. El caos de una distribución territorial nómade necesita de un anclaje retórico. De ahí que se genere la impresión de un paisaje vacío por medio de la acumulación de elementos naturales en antagonismo con lo civilizado. El naturalista escribe en su diario: "Las obras inanimadas de la Naturaleza -rocas, hielo, nieve, viento, y agua- todas en guerra entre sí, pero coligadas en contra del hombre, aquí reinaban en absoluta soberanía." (Darwin, 1909, p. 247).

La misma evocación desolada de Darwin influirá viajes posteriores. La trama inhóspita de la Patagonia repetirá su efecto con medios diversos sobre la sensibilidad de otros exploradores. Darwin profundiza la imaginación topológica sobre estas tierras, mediante el gesto de vaciar un territorio que resiste a todo vínculo con el ser humano, en la imposibilidad de constituirse como paisaje.

La escritora británica Lady Florence Dixie narrativiza nuevamente la Patagonia. Luego de visitar el sector, durante 1878-1879, escribe Across Patagonia. Dixie contempla los paisajes patagónicos motivada por la lectura de Darwin, a quien escribe una serie de cartas relatando sus observaciones zoológicas (Martinic, 2009). La óptica del paisaje vacío vuelve en su escritura.

Florence Dixie tenía motivaciones diplomáticas y militares. Enviada por el gobierno británico, la exploradora describe pacientemente la geografía de la zona austral del continente americano. Sus primeras impresiones del estrecho de Magallanes muestran la paradoja de aquel terri- torio. Los ojos metropolitanos de Dixie articulan el panorama como una tierra abandonada y miserable. Esta imagen no impide que los montículos eriazos se marquen intensamente en su memoria.

\begin{abstract}
¡Patagonia, por fin! Bastante desolada y triste se veía, una sucesión de planicies desnudas, ni un árbol ni un arbusto visible en ninguna parte; tal paisaje, de hecho, como el que uno esperaría encontrar en otro planeta. Y aunque había sido muy impresionada por el brillo y la exhuberancia de la vida tropical en Río, la impresión que dejó en mi mente tuvo que ceder en intensidad a los vagos sentimientos de admiración y asombro producidos por la visión de las yermas soledades ahora frente a mí. (Dixie, 1880, p. 29).
\end{abstract}

Habría que preguntarse la manera específica en que la escritora produce su descripción. En la misma línea de Darwin, la representación de estos elementos nómades es articulada en un paisaje que tiende al vacío. Quizá la marca más segura de que estamos ante este efecto sea la transferencia entre formatos escritos y visuales. Las correspondencias en la producción de objetos culturales frente a una misma geografía revelan la intensidad de las impresiones marcadas en la sensibilidad de los exploradores. Resulta curioso reunir en una lectura las ilustraciones del ingeniero Julius Beerbohm, quien acompaña a Florence Dixie en su viaje, con las descripciones de la escritora. Una notoria paridad asemeja las representaciones del estrecho de Magallanes. En los grabados de Beerhom, el grabador torna semejantes las olas y las hojas de los árboles. Pareciera que la amplitud del agua amenaza con tragar cada uno de los objetos del territorio, fundiendo el grabado en una tonalidad gris y movediza. De manera similar, Florence Dixie describe la entrada al Estrecho,

A lo largo de la costa la tierra termina abruptamente, y los árboles y arbustos forman una espesura impenetrable, que desciende casi hasta el límite del agua. Punto por punto penetran en el mar, cada uno soportando una monótona semejanza 
al otro, aunque, mientras avanzábamos, la vegetación que las cubría crecía más y más atrofiada y escasa, hasta que por fin los árboles y arbustos desaparecían por completo (Dixie, 1880 , p. 41).

Brasil, Montevideo, la América exótica a ojos de Florence Dixie, se compone de colores brillantes y bien delimitados (Dixie, 1880). La Patagonia, en cambio, es el lugar donde todas las criaturas se confunden en una única gama de color. Sin orientación alguna, la visualidad repetitiva recrea el espacio nómade por medio de un paisaje vacío.

La última de esta serie de crónicas patagónicas que recuperamos en este estudio vuelve al tópico del paisaje vaciado, pero con matices. Mediante un accidentada navegación, William Hudson llega al valle de Río Negro, ahora en la zona norte de la Patagonia, décadas después de Darwin y algunos años de Dixie. En forma de prefacio a la extensa écfrasis que es Idle Days in Patagonia (1893/1923), Hudson muestra al lector la finalidad de visitar tan remotas tierras, "¡Tantas veces había representado en $\mathrm{mi}$ imaginación, deseando intensamente visitar esta salvaje tierra solitaria, descansar lejos en su paz primitiva y desolada, no tocada por la mano del hombre, y remota de la civilización!" (Hudson, 1893/1923, p. 5).

Hudson registra las leyendas que constituyen la alegoría inhóspita de la Patagonia; la mítica ciudad de Trapalanda, la figura inmensa de los gigantes que, según Pigaffeta, vio Magallanes. Pero no son estos relatos los que motivan su viaje. Hudson busca recopilar información sobre las aves del sector. Sin embargo, un infortunado accidente lo obliga a convertirse en un "ocioso" (idler), especie de dandy en condiciones geográficas extremas. Bajo el influjo de la inmovilidad física, el científico amplía su objeto de estudio representando el territorio desde una distribución nómade. No tan solo su cuerpo se desplaza, sino también su objeto de estudio. De ahí que se permita desplazar su concentración en formas inéditas, sin privilegiar ninguna impresión sobre otra. Explica Hudson,

No capturé nada ni descubrí nada; sin embargo, estos días de ociosidad forzada no fueron infelices. Y después de dejar mi habitación, cojeando por los alrededores con la ayuda de un sólido bastón, y sentándome en casas, me relacioné con hombres y mujeres, y escuché día tras día la historia de sus pequeños y poco aviares asuntos, hasta que empezó por interesarme. Pero no profundamente. Siempre podía abandonarlos sin arrepentimiento alguno para recostarme en el verde césped, para mirar los árboles o el cielo azul, y especular sobre toda clase de cosas imaginables. (Hudson, 1893/1923, p. 20)

De esta forma, Hudson relata su conversión hacia un estado mental ocioso, o en términos de Deleuze, nómade. Los tratos descuidados con los habitantes del sector devienen en largos paseos por el lugar. La distracción admite la emergencia de un paisaje intelectual que confunde los bordes de los diferentes objetos que lo componen. Al abandonar los retratos seguros, la escritura genera atmósferas. La impresión fundamental será la presencia de la llanura austral y sus extensas planicies vacías, a las que estará dedicado todo el capítulo octavo. En el valle mismo, Hudson cumple con las metas que se había puesto al llegar a la región. Caza y estudia aves rigurosamente. Pero en su estado ocioso, las expediciones científicas se transforman en paseos. El científico internaliza los estímulos de la naturaleza. La geografía reordena su paisaje mental: "Lo que verdaderamente ha ingresado a nuestra alma y se ha vuelto psíquico es nuestro ambiente - aquella naturaleza salvaje en la cual y por la cual hemos nacido en un remoto periodo inconcebible, y que nos hizo lo que somos" (Hudson, $1893 / 1923$, p. 225). Como observador, el naturalista extrae su conocimiento del territorio desde una cómoda distancia con el objeto, lo que permite analizar cada uno de sus componentes por separado. El nómade, en cambio, lejos de ordenar y privilegiar los objetos, se mezcla con ellos.

Hudson ingresa a la estepa austral en la que cree percibir sentimientos atávicos que conectan al ser humano con sus antepasados salvajes. Se abandona periódicamente a la intemperie, en circuitos repetitivos, y retorna únicamente cuando es necesario: "No una vez, no dos, no tres, sino día tras día volví a esta soledad, yen- 
do a ella en la mañana como si asistiese a un festival, y dejándolo solamente cuando el hambre y la sed y el sol poniente me empujaban a hacerlo" (Hudson, 1893/1923, p. 211). Los paseos no tendrán ningún propósito. Aunque lleva un arma, no se interesa en la cacería. Sin destino, el recorrido mismo se vuelve la meta, " $y$, sin embargo, no tenía ningún objeto en ir la las planicies patagónicas] - ningún motivo que pudiera ponerse en palabras" (Hudson, 1893/1923, p. 211).

La preocupación de Hudson evita narrar el viaje como un apéndice de la herencia occidental. Ni mito, ni ciencia. Percibe la posible diferencia a la que se enfrenta el lenguaje en condiciones de intensidad concentrada de la atención geográfica. Pero las impresiones no pueden ser completamente inéditas, si no sería imposible ponerlas por escrito, donde los seguros caminos de la tradición son insuficientes, las rutas nómades generan la sensibilidad.

\section{DOS ULISES: NOMOS Y GNOSIS COMO ORGANIZACIÓN TERRITORIAL}

Como dijimos antes, la Patagonia goza de su propia monotonía. Territorios grises y derruidos. Tierras yermas, incluso miserables para la perspectiva modernizadora de los británicos. Cada uno de los viajeros reconoce su asombro en este déficit y conciben, por tanto, un paisaje vacío. Sin embargo, existe una correspondencia que podría servir para explicar la cualidad distintiva de estos parajes. Tanto Florence Dixie como William Hudson utilizan un giro muy específico para declarar los tonos emotivos de su llegada a la Patagonia. Dixie exclama "Patagonia at Last"; Hudson repite "At last, Patagonia!" ¿Qué atrae en esta insistencia formal a los escritores viajeros?

La explicación debiese tomar en cuenta la experiencia de lectura de los autores en Inglaterra. William Cowper traduce la Odisea de Homero en 1791. Leyendo el diálogo entre Odiseo y Atenea, en esa versión, encontramos un motivo clásico que parte en la Odisea, pero que se transmite a través de Ovidio y Virgilio hacia el resto de Oc-

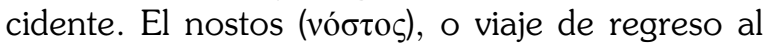
hogar, es el tópico que moviliza el poema homérico. Una vez que Odiseo presencia las antiguas comarcas pregunta a Atenea si las piedras en su presencia lo engañan, pues duda si efectivamente ha llegado a Ítaca. Cowper traduce la exclamación de Odiseo como "My long-reggreted home at last!"(Cowper, 1791/1809, p. 18). La herencia occidental constituirá gran parte de su horizonte cultural tras este motivo. Tal como lo ha descrito McConell (1986):

Nostos es la palabra griega que significa 'vuelta a casa' o 'llegada a casa', la raíz de nuestra palabra 'nostalgia'. Es la palabra tradicionalmente aplicada al momento de la Odisea cuando Ulises reestablece su reino de Ítaca e, implícitamente el orden del universo. Ambas, gnosis y nostos, son términos no bíblicos. Y si el primero implica un viaje de conocimiento e iluminación más allá de los limites de lo conocido o articulable, el otro es su complemento ideal al, implicar un viaje a casa luego del inefable regreso a la certitud de lo cotidiano. (McConell, 1986, p. 15).

En el relato de McConell, el retorno a casa será también la metáfora que organizará el mensaje que en la tradición mosaico cristiana de la divinidad con su pueblo. "Home at last", por lo tanto, es la sinécdoque del viaje de Odiseo. El héroe abandona los placeres eternos de la isla de Circe, la hospitalidad de los Feacios, las riquezas de reinos más prósperos por volver al hogar. " $\mathrm{Pa}$ tagonia at last!" Es la inversión de este motivo. El explorador busca lo inhospitalario. Prefiere lo novedoso a lo reconocible. Las piedras del Ulises de Cowper reemplazan los recuerdos de la madre patria, o de la maternal amante que es Penélope. El viajero mantiene su deseo para consumarlo en el retorno a los conceptos conocidos y sedentarios del hogar. La Patagonia, en cambio, es el territorio yermo, o en términos de los viajeros ingleses estudiados, el paisaje vacío. La incomodidad advierte al explorador que debe moverse. No es extraño, entonces, que Hudson crea volver a un estado salvaje, o que Darwin y Dixie queden simplemente estupefactos. El ornitólogo se identifica con los habitantes indígenas de la Patagonia, pero no es la barbarie lo que inspira y excita la imaginación impresionista de Hudson, sino el nomadismo ante el territorio y la crisis conceptual que proyec- 
ta. En contra de toda cartografía estática, la Patagonia requiere una escritura similar a la descrita por Deleuze quien la sistematiza y describe como una distribución nómade. Una escritura que se va forjando a medida que se experimenta el territorio, cuya lectura exige una perspectiva geocrítica o geopoética (White, 1992; Westphal, 2001). En lugar de nostos, la escritura nomádica sigue el camino de la gnosis ( $\gamma v \tilde{\omega} \sigma 1 \varsigma)$, es decir, un viaje de conocimiento e iluminación más allá de los límites de lo conocido.

Mientras que Pigaffeta descubre el paisaje patagónico desde un imaginario europeo, siempre con miras al retorno al hogar, en el caso de los viajeros ingleses, es el territorio el que altera su sensibilidad y, por tanto, los imaginarios literarios heredados. Las frases de Hudson y Florence Dixie, "Patagonia at last" configuran un nuevo tópico dado por la inversión del motivo clásico. Ya no la vuelta a casa, sino una experiencia que altera las categorías de conocimiento y obliga a una migración conceptual. De esta inversión viene la motivación del explorador de habitar espacios inhóspitos. Los paisajes vacíos, los "arid wastes" de Darwin, o las "bare plateaus" de Dixie trazan la cartografía de un espacio inédito normalizado por las coordenadas universales. Entonces en lugar de un conocimiento que quiere volver a casa, un conocimiento sedentario, estos viajeros ingleses realizan su experiencia en un conocimiento arriesgado, hacia el nomadismo intelectual.

La inversión del territorio altera la lógica de los materiales que componen el paisaje descrito por los exploradores. El artista extiende el lienzo para llenar el espacio con objetos naturales. La Patagonia exige lo contrario. Los escritores refieren a objetos, pero el efecto será vaciar el espacio de visualidad. La repetición y la monotonía cromática reemplazan los contrastes. Los exploradores extirpan todo dramatismo humano de las escenas para quedarse con la vastedad del territorio. El campo visual se reduce a un gesto semejante a entrecerrar los ojos: los matices se diluyen, se reconocen las formas. De alguna manera, los relatos simulan la simpleza del boceto antes de aplicarse el color. La experiencia estará compuesta por tramas básicas, perfectamente distinguibles, entrecruzando las poéticas de lo geográfico, así como una elaboración de la presencia del paisaje como determinante estética cifrada y yerma, imborrable.

\section{BIBLIOGRAFÍA}

Chatwin, B. (2005). En la Patagonia. En Los viajes. Barcelona: Ediciones Península. Publicado originalmente en 1777.

Cowper, W. (1809). The Iliad and Odyssey [and The battle of the frogs and micel tr. into Engl. blank verse. William. London: J. Johnson, St. Paul's Churchyard. Publicado originalmente en 1791.

Cosgrove, D. (2008). Geography \& Vision: Seeing, Imagining and Representing the World. London, New York: I.B. Tauris.

Darwin, C. (1909). The Voyage of the Beagle. New York: P.F. Collier \& Son Corporation.

Peter Dear (2015) Romanticism and Victorian Scientific Naturalism. European Romantic Review, 26(3), 329340 ,

Deleuze, G. (2002). Diferencia y repetición. 1968. Buenos Aires: Amorrortu. Publicado originalmente en 1968.

Dixie, F. (1880). Across Patagonia. London: Richard Bentley and Son.

Harambour R, Azara, A., Harambour, M., \& Azara, M. (2015). Memorias de William Blain en Malvinas y Patagonia (c.1881-1890). Magallania, 43(2), 223-249.

Hudson, W. (1923). Idle days in Patagonia. London: J. M. Dent \& Sons Ltd. Publicado originalmente en 1893.

Livon-Grosman, E. (2003). Geografías imaginarias: el relato de viaje y la construcción del espacio patagónico. Rosario: Beatriz Viterbo.

Malvestitti, M. (2010). Lingüística misionera en Pampa y Patagonia (1860-1930). RAHL: Revista argentina de historiografía lingüística, 2(1), 55-73.

Martinic, M. (2009). Cartas de Lady Florence Dixie a Charles Darwin. Magallania, 37(1), 221-222.

Martinic, M. (2002). La participación de capitales británicos en el desarrollo económico del territorio de magallanes (1880-1920). Historia, 35, 299-321.

McConnell, F. D. (1986). The Bible and the Narrative Tradition. Oxford: Oxford University Press.

Paradis, J. (1981). Darwin and landscape. Annals of the New York Academy of Sciences, 360(1), 85-110.

Pigafetta, A. (1986). Primer viaje alrededor del Globo. Barcelona: Orbis. Publicado originalmente en 1536.

Pratt, M. L. (2008). Imperial eyes: Travel writing and transculturation. New York: Routledge. Publicado originalmente en 1992.

Rojas Mix, M. (1992). América Imaginaria. Barcelona: Lumen, 
1992.

Ruskin, J. (2007). Lectures on landscape. Gloucestershire: Dodo Press. Publicado originalmente en 1871.

Stafford, B. M. (1984). Voyage into Substance: Art, Science, Nature, and the Illustrated Travel Account, 1790-
1840. Cambridge: MIT Press.

White, K. (1992). "Elements of Geopoetics", Edinburgh Review, 88, 163-8.

Westphal, B. (2001). Geocriticism: real and fictional spaces. New York: Palgrave Macmillan. 
